East African Medical Journal Vol. 84 No. 8 August 2007

RECONSTRUCTION OF URETHRAL INJURIES

G.A. Maranya, MBChB, MMed, Cert. Urol.(E.A.), FCS (ECSA), Y.A. Al-Ammary, MBChB, MMed and P.R. Oduor, MBChB, MMed, FCS(ECSA), Consultant Surgeons, Coast Province General Hospital, P.O. Box 91066-80103, Mombasa, Kenya

Request for reprints to: Dr. G.A. Maranya, Coast Province General Hospital, P.O. Box 91066-80103, Mombasa, Kenya

\title{
RECONSTRUCTION OF URETHRAL INJURIES
}

\author{
G.A. MARANYA, Y.A. AL-AMMARY and P.R. ODUOR
}

\begin{abstract}
Objectives: To highlight the complexity of urethral injuries and to emphasise their prevention. Design: A retrospective study.

Setting: Coast Province General Hospital, Mombasa, Kenya.

Subjects: Twenty two male patients operated between 1997 and 2007.

Results: Surgery for urethral injuries was done on 22 patients; 16 were of the posterior urethra, five bulbar urethra and one proximal penile urethra. The posterior urethral injuries were due to: pelvic fracture in 14, penetrating stick in one, and one animal injury by a buffalo. The bulbar urethral injuries were due to straddle injuries in four and one gunshot injury. The penile urethral injury was by compression of the subject by a motor vehicle against a wall. Anastomotic urethroplasty was performed in 20 patients, of whom 16 had complete recovery. Surgery for all bulbar and the penile urethral injuries was successful. Failure of repair with restenosis occurred in four patients with posterior urethral injuries. Bouginage was done in one patient who subsequently required no further treatment. Eventual total obliteration occurred in three patients. Reoperation was done in two of these with complete recovery in one and failure in the other who had two further urethroplasties, optical urethrotomy and is currently on clean intermittent self catheterisation. The fourth patient awaits reoperation. Sutureless membranous urethroplasty was done in two patients with posterior urethral injuries in whom sutures could not be inserted into the proximal prostatic urethra. One developed stenosis a year later, had optical urethrotomy and commenced on clean intermittent self catheterisation for a while, without further trouble. The other developed total obliteration. At repeat surgery enhanced scarring with urethral shortening were found and the operation was abandoned. The Mitrofanoff principle was applied with an appendicovesicostomy; one form of urinary diversion with a continent catheterisable conduit. On follow up, now nine years, the diversion is continent, has no catheterisation difficulties, and no urinary calculi.

Conclusion: Urethral injuries are difficult to manage. A two pronged approach is advanced; prevention and competent repair. Surgeons managing these injuries are encouraged to acquire the needed reconstruction skills. Emphasis on prevention is paramount. Appropriate road, industrial and occupational safety measures should be enforced. Iatrogenic injuries can be avoided by due care during catheterisation and urethral instrumentation.
\end{abstract}

\section{INTRODUCTION}

Injuries to the urethra occur from external blunt or penetrating trauma, and internal injury, usually iatrogenic (1). Anterior urethral injuries usually result from blunt trauma, fall astride, kicks in the perineum, penetrating trauma due to gunshot or stab wounds, iatrogenic injuries from urethral catheters, catheterisation and endoscopic instrumentation. Posterior urethral injuries are associated with 
pelvic fracture due to road traffic accidents, falls from heights, industrial accidents, and penetrating gunshot or stab wounds.

Injury to the female urethra after a pelvic fracture is rare, partly because of the short mobile urethra which lies behind and is protected by the pubic bone and partly because of the lower incidence of trauma in females $(2,3)$. Female urethral injury after pelvic fracture predominates in children and young adolescents probably because of the thinner, more delicate and less mobile prepubertal vagina.

Urethral injuries in children tend to follow the same mechanism of injury as adults $(1,3,4)$. Urethral injuries must be suspected in any patient with fracture of the pelvis, blood at the urethral meatus, difficulty or inability to void, a palpable bladder from distention, perineal bruising, a high riding prostate on digital rectal examination, fractures involving displacement of the pubic rami relative to the rest of the pelvis and pelvic haematoma (1).

The initial management of all urethral injuries is resuscitation of the patient as a result of associated injuries which can be life threatening $(1,3)$. This is especially so for posterior urethral injuries because of their close association with pelvic fractures and other intra-abdominal and orthopaedic injuries.

The recommended treatment protocol of urethral disruption is based on the Johanson principle, with a cystostomy at the time of injury, postponing the reconstruction of urethral continuity (5).

Timing of surgical intervention has been defined into: immediate treatment which is done less than 48 hours after injury, delayed primary treatment between two and 14 days, and deferred treatment at three months or more (1). Immediate or delayed primary repair has a high incidence of strictures, incontinence and impotence, whereas deferred treatment in experienced hands has a low rate of restenosis, impotence and incontinence $(1,3)$. This however, does not apply to urethral injury in female patients where immediate repair or realignment is done to preserve urethral length, minimise periurethral fibrosis and maintain vaginal patency (2).

In young children, especially in those with severe injuries, the Mitrofanoff principle should be applied. This entails fashioning of a continent catheterisable conduit, usually appendix between the bladder and skin; appendicovesicostomy (5). This provides for satisfactory bladder drainage by intermittent catheterisation in case of voiding difficulties after urethral surgery or if there is failure of repair.

A one stage perineal end to end anastomosis is the recommended surgical treatment. This elaborated perineal approach, through four main technical stages, applies surgical manouvres necessary to accomplish a tension free anastomosis, stopping at the stage which first achieves this (6). The first step is simple urethral mobilisation with anastomosis of the spatulated healthy ends. The second step develops the intercrural space to accommodate the mobilised urethra thereby reducing the length of the defect. The third step further reduces the gap by resecting the inferior aspect of the symphysis pubis. If this still does not give a tension free anastomosis then the fourth and final technical step is to reroute the urethra around one corpus cavernosum.

\section{MATERIALS AND METHODS}

The patients presented were operated by the authors between 1997 and 2007, at the Coast Province General Hospital, Mombasa, Kenya.

All the patients had deferred surgical treatment; that is, surgery at least three months after injury. The patients had a suprapubic catheter except two with bulbar urethral injuries who had one inserted at urethroplasty. All the patients had preoperative urethrograms and some had simultaneous suprapubic cystography and an ascending urethrogram ('up-and-downogram').

A total of 22 male patients were operated over this period. Of these, 16 had posterior urethral disruption; 14 due to pelvic fracture; one perineal penetration on falling from a height onto a stick and one animal injury by a buffalo.

Bulbar urethral injuries occurred in five patients; four due to straddle injuries and one gunshot injury with associated fracture of the right proximal femur. A proximal penile urethral injury occurred in one patient who was compressed against wall by a motor vehicle and also sustained fractures of the right superior and inferior pubic rami but no posterior urethral injury. The low lithotomy position which entails modest flexion at the hips and knees was used at surgery. Heparin was administered for prophylactic anticoagulation and perioperative antibiotics given. All the patients were operated through a midline perineal incision. Anastomotic urethroplasty was performed on 20 patients, applying the elaborated perineal approach (Figure 1). 
Figure 1

Posterior anastomotic urethroplasty. a) Positioning. Low lithotomy. b) Midline perineal incision. c) Urethral mobilisation. d) Division of bulbar urethra at point of obliteration. Excision of scar tissue to expose the prostate. e) Incision of the prostatic urethra with the guide of a suprapubic bougie.f) Sutures are placed through the prostatic urethra. Separation of the crura. Spatulation of the bulbous urethra.g) Same sutures are placed through the bulbous urethra and tied to complete the anastomosis. $h$ ) The bulbous urethra is hitched to the crura. Urethral catheterisation, which may also be done before tying the last few sutures.

(a)

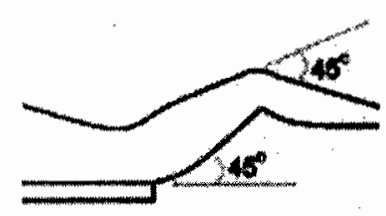

(b)

(e)

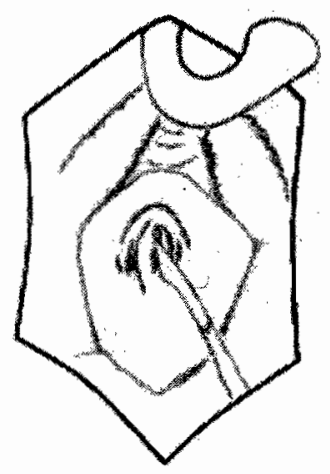

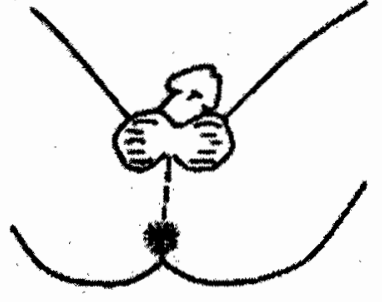

(f)

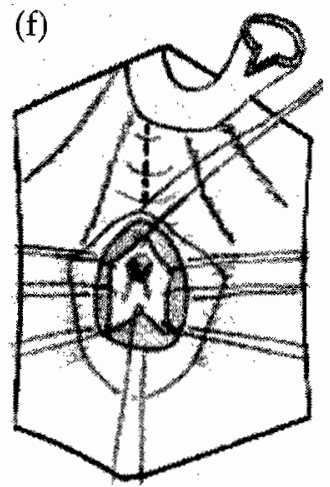

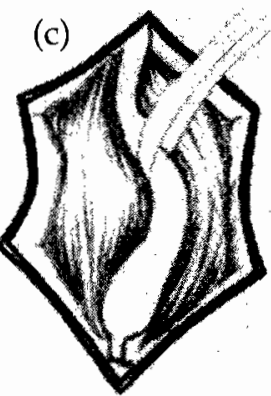

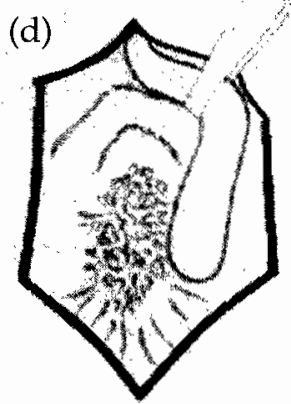

(g)

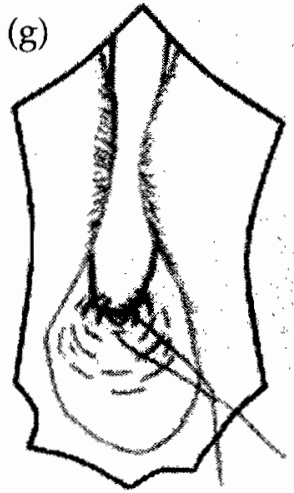

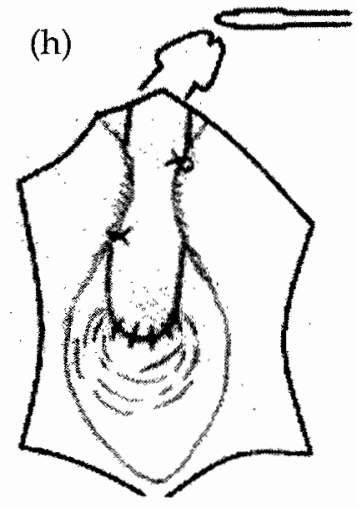

In two patients, it was impossible to insert proximal sutures into the prostatic urethra. Previous surgery elsewhere had been done in one patient. The other, aged 49 years old, had extensive scarring and total impotence following pelvic fracture. Sutureless membranous urethroplasty was done on them; where the mobilised bulbar urethra was sutured onto a Foley catheter with rapidly absorbable suture which was then introduced into the bladder and the balloon inflated to appose the bulbous and prostatic urethral ends.

\section{RESULTS}

All the 22 patients were male; their ages ranging from 13 to 49 years with a mean of 29 years. As most patients had a suprapubic catheter, there was little threat to the upper urinary tracts. No patient had renal impairment or renal failure. Asymptomatic bacteriuria was assumed but no treatment given.
Antibiotic therapy was commenced if a patient had fever, suprapubic pain or grossly turbid urine.

Thelength of urethral defect did not correlate with the appearance of the synchronous urethrograms. Since bulbous urethral elasticity can yield one to two centimetres and straightening of the bulbous urethral curve by crural separation an additional two to four centimetres it can be deduced that all the strictures were less than five centimetres as no manouvres beyond crural separation were carried out. The bulbous urethral strictures or distractions were short and their repairs easier than the posterior urethral disruptions which were longer, more complex and difficult to repair. Patients with comminuted pelvic fractures or severe displacement had extensive scarring implied by the severity of trauma.

All the five bulbar and one penile urethral injuries had a successful outcome after anastomotic urethroplasty. Of the 14 patients with posterior urethral distraction defects, ten had a successful 
urethroplasty. Of the 14 patients with posterior urethral distraction defects, ten had a successful outcome after surgery. Many patients in this group were reluctant to have a post-operative urethrogram because they were asymptomatic and the cost factor. Representative pre-operative and posto-perative urethrograms and an immediate

\section{Figure 2}

Pictures of a 30 year old patient with pelvic fracture posterior urethral injury

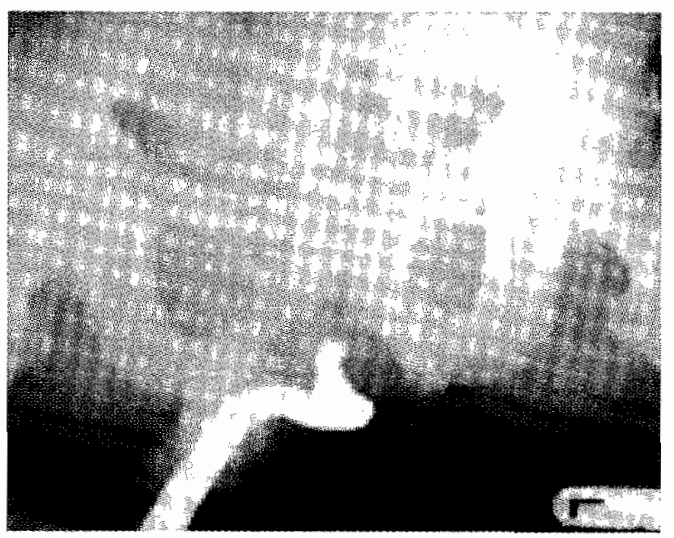

Figure 2a: Pre-operative urethrogram showing complete obliteration of urethra

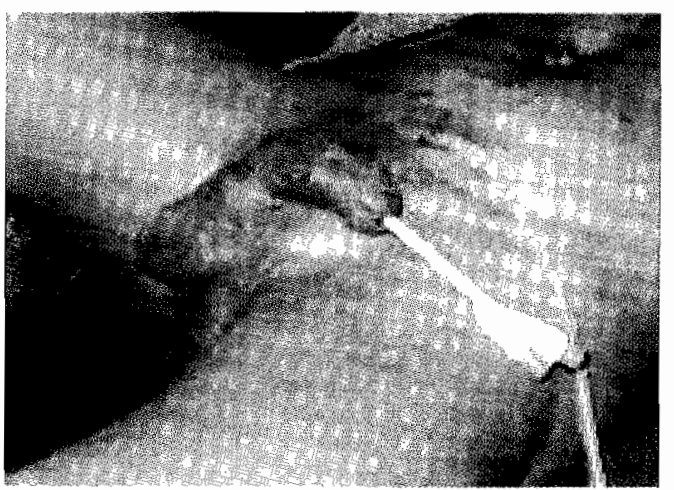

Figure 2b: Immediate post-operative picture with the urethral stent and suprapubic catheter

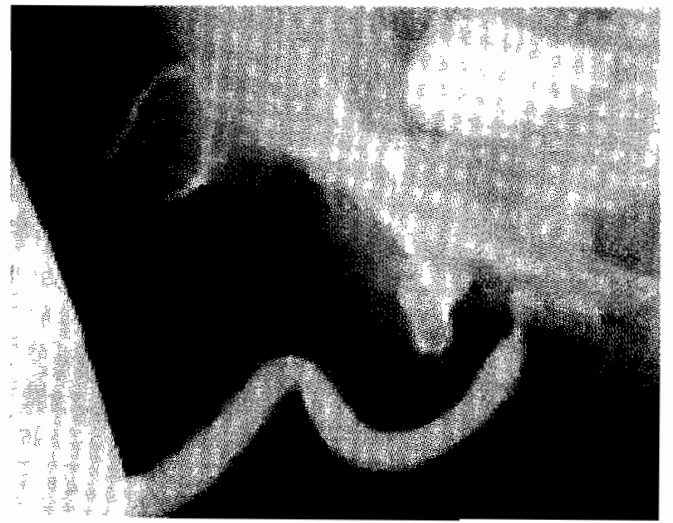

Figure 2c: Post-operative urethrogram confirming a successful outcome
Figure 3

Appendicovesicostomy of the 49 year old patient

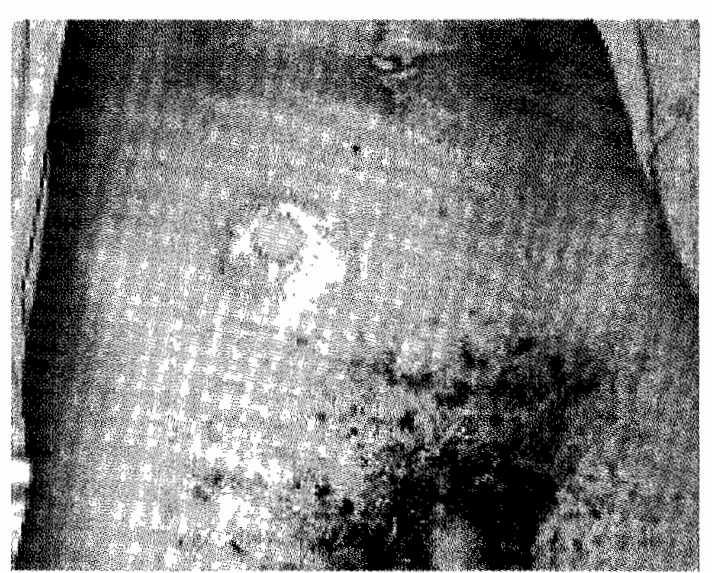

Figure 3a: Stoma 8 years post-operatively

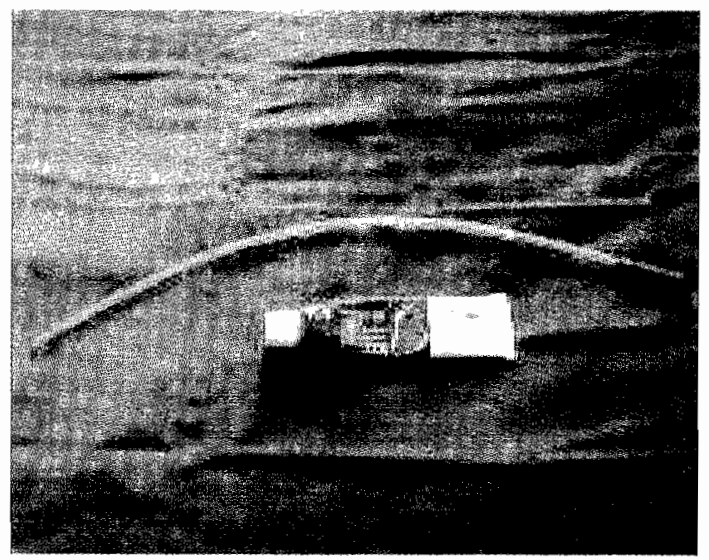

Figure 3b: Nelaton catheter and lubricant for catheterising the stoma

post-operative picture of a 30 year old patient are shown (Figure 2).

Failure of repair with restenosis occurred in four patients. One patient had bouginage once and no further problem. One patient with restenosis had bouginage and commenced on clean intermittent self catheterisation but developed total blockage a year later. He had a repeat anastomotic urethroplasty which was successful, but developed erectile dysfunction with weak erections. One 14 year old boy with posterior urethral injury associated with a severely displaced pelvic fracture had laparatomy for associated abdominal injuries at which a large pelvic haematoma was also found. At urethroplasty four months later, extensive scarring was encountered. He was commenced on twice weekly catheterisation 
catheterisation failed. At one year after surgery he had total blockage. He was sent to Kilimanjaro Christian Medical College, Moshi, Tanzania, for surgery by a visiting British urological team, who performed anastomotic urethroplasty. On removal of the urethral catheter three weeks after operation, he voided for two days and developed blockage. A urethrogram showed obstruction at the same site as before. He had a third urethroplasty by a visiting Danish urological team but he developed a stricture after about six months. Optical urethrotomy was done in May 2007 and the patient is currently on clean intermittent self catheterisation. One 24 year old patient with pelvic fracture and posterior urethral injury also had traumatic paraparesis and was wheel chair bound. At surgery, the prostatic urethra was also found to be scarred. Upon removal of the urethral catheter, he voided well for two weeks then developed obstruction. A urethrogram showed total obliteration in the posterior urethra. He awaits another surgical procedure.
Of the two patients who had sutureless membranous urethroplasty, the one who had had previous surgery developed a membranous stricture about a year later. He had optical urethrotomy and did clean intermittent self catheterisation for a while. He has been on follow up for eight years now with no further trouble. The second patient with pelvic fracture and total impotence developed complete obliteration of the repair. At a second operation enhanced scarring and urethral shortening were found. The operation was abandoned. A Mitrofanoff procedure, as an appendicovesicostomy was performed to divert the urine (Figure 3 ). In the course of these treatments the wife died of an illness. The diversion is continent, has no catheterisation problems and has not developed urinary calculi after nine years of follow up to date. Annual irrigation of the urinary bladder is done to minimise the chance of bladder calculi development.

No patient developed post-operative urinary incontinence. A summary of the results is shown in Table 1.

Table 1

Results of surgery for urethral injuries

\begin{tabular}{|c|c|c|c|c|c|}
\hline $\begin{array}{l}\text { Age } \\
\text { (year) }\end{array}$ & Site of injury & Mechanism & Operation & Outcome & Comment \\
\hline Range & & $\begin{array}{l}\text { Pelvic fracture } \\
(\mathrm{n}=14)\end{array}$ & $\begin{array}{l}\text { Anastomotic } \\
\text { urethroplasty }\end{array}$ & $\begin{array}{l}\text { Complete } \\
\text { recovery }\end{array}$ & $\begin{array}{l}1 \text { case: bouginage once, no further } \\
\text { problem. }\end{array}$ \\
\hline $13-49$ & $\begin{array}{l}\text { Membranous } \\
(\mathbf{n}=16)\end{array}$ & $\begin{array}{l}\text { Penetrating stick } \\
(\mathrm{n}=1) \\
\text { Animal; buffalo } \\
(\mathbf{n}=1)\end{array}$ & $(n=20)$ & $\begin{array}{l}(n=16) \\
\text { Restenosis } \\
(n=4)\end{array}$ & $\begin{array}{l}2 \text { cases: intermittent catheterisation } \\
\text { - eventual total blockage. Repeat } \\
\text { surgery - } 1 \text { good result and } 1 \text { failure. } \\
2 \text { further urethroplasties. Stricture. }\end{array}$ \\
\hline \multirow{6}{*}{$\begin{array}{l}\text { Mean } \\
29\end{array}$} & \multirow{5}{*}{ Bulbar $(n=5)$} & & & & Optical urethrotomy. On clean \\
\hline & & & & & intermittent self catheterisation. \\
\hline & & Straddle $(n=4)$ & & & $\begin{array}{l}1 \text { case: blockage shortly after } \\
\text { operation; awaits repeat surgery. }\end{array}$ \\
\hline & & Gunshot $(\mathrm{n}=1)$ & \multirow{3}{*}{$\begin{array}{l}\text { Sutureless } \\
\text { membranous } \\
\text { urethroplasty } \\
(\mathrm{n}=2)\end{array}$} & & Optical urethrotomy then clean \\
\hline & & & & $\begin{array}{l}\text { Restenosis } \\
(\mathrm{n}=1)\end{array}$ & $\begin{array}{l}\text { intermittent self catheterisation. No } \\
\text { further problem; } 8 \text { years of follow } \\
\text { up. }\end{array}$ \\
\hline & Penile $(n=1)$ & $\begin{array}{l}\text { Compression onto } \\
\text { a wall by a motor } \\
\text { vehicle }(n=1)\end{array}$ & & $\begin{array}{l}\text { Total } \\
\text { obliteration } \\
(n=1)\end{array}$ & $\begin{array}{l}\text { Appendicovesicostomy diversion; } \\
\text { Mitrofanoff. No diversion } \\
\text { complications; } 9 \text { years of follow up. }\end{array}$ \\
\hline
\end{tabular}




\section{DISCUSSION}

The surgical management of urethral injuries is difficult and presents one of the most challenging problems in urology.

Most urethral injuries in our series were of the posterior urethra; 16 of $22(73 \%)$. This compares to $69 \%$ of the series by Hafez et al (4). The pre-operative urethrograms did not usually predict the extent of surgery to be performed (7). The radiological measurement of the defect did not correspond to the operative findings. In some synchronous urethrograms the cystograms did not outline the posterior urethra. Also at surgery scarred urethra had to be trimmed back to healthy tissue thus increasing the gap. The bulbous urethral strictures or distractions due to straddle injuries were short. This is because the two urethral ends remain fixed in position by their attachment via the dorsal midline raphe to the corpora cavernosa. However, after pelvic fracture there is distraction and deformity of the posterior urethra which may be associated with upward displacement of the bladder and prostate and with retropubic haematoma. In many cases the stricture was found to be more posterior than anticipated. This makes it important for the operator to be familiar with the progressive stages of surgery, namely: urethral mobilisation, crural separation, inferior pubectomy and urethral re-routing to achieve a tension free anastomosis (6).

It was tempting to consider optical urethrotomy for the bulbous urethral strictures, but this is not advisable as it often fails and jeopardises future anastomotic urethroplasty due to enhanced scarring (8).

Anastomotic urethroplasty was used in 20 of our 22 cases (91\%). Anastomotic urethroplasty using a one stage perineal approach is the best treatment for post traumatic urethral strictures and is regarded as the gold standard to which other procedures are compared $(1,9)$. The long term results are excellent compared to substitution urethroplasty with buccal mucosa, skin or skin flaps $(4,10)$.

The low lithotomy position used at surgery ensured gentle flexion at the hips and knees (11). This aimed at minimising the complications of positioning such as compartment syndrome, rhabdomyolysis, neuropathy, deep vein thrombosis and severe low back pain (12), often associated with standard lithotomy and more so with exaggerated lithotomy.
At surgery we strived to excise all the fibrous tissue occupying the distraction as well as the scarred urethra and to achieve a wide, oblique, tension free anastomosis $(6,9,13)$. For the bulbous urethral strictures, urethral mobilisation was all that was needed, while the posterior urethral distraction defects required crural separation as well. Inferior pubectomy or urethral re-routing was not required in any of our cases. All bulbar and the penile urethral repairs had a successful outcome. Surgical success is defined as asymptomatic voiding with no clinical evidence of residual stricture (4). Our primary success rate for posterior urethral distraction defects was 12 out of $16(75 \%)$, compared to Webster and Ramon (6), who had a high success rate of $96 \%$, and Koraitim (9) with $93 \%$ success.

If the anastomotic repair fails, a repeat procedure is advocated using the same principles (14). Of the two repeat urethroplasties one succeeded while the other failed and was subjected to two further procedures of the same.

Perineo-abdominal transpubic procedures or substitution urethroplasties were not considered in our series. The sutureless membranous urethroplasty (15) was used in extreme situations but this procedure would nolonger be recommended. The Mitrofanoff principle of appendicovesicostomy applied on one of the patients is sometimes advocated as one form of suprapubic urinary diversion for the completely hopeless urethra (12). Our overall success rate was 19 out of $22(86 \%)$. This compares to Hafez's et al (4) $89 \%$ overall success.

Post-operative impotence which occurred in one patient is reported in about $5 \%$ of cases after urethroplasty but resolves within a year in most cases (13). Patients should be warned of this risk.

Overall, pelvic fracture urethral trauma is uncommon. Even experts in the field perform surgery on only a few cases per year (16). In this survey done in the United Kingdom only four urologists (2\% of responders) saw three or more cases per year, another four saw one or two cases per year and only three surgeons performed more than five procedures per year.

In conclusion, urethral injuries present a difficult surgical challenge. Surgeons that deal with this problem are encouraged to learn the required reconstruction techniques. Emphasis is on the prevention of these injuries by effecting road, 
industrial and occupational safety measures. Iatrogenic injuries can also be prevented. Urethral catheterisation with an adequate size catheter should be done after generous lubrication of the urethra with anaesthetic gel. Urethral instrumentation is to be done gently, with appropriate size devices, after thorough lubrication.

\section{ACKNOWLEDGEMENTS}

We are grateful to Samora Maranya for the drawings and Jason Mwawana for the computer work. We thank the Chief Administrator of Coast Province General Hospital, Mombasa for permission to publish this work.

\section{REFERENCES}

1. Chapple C.R., Barbagli G., Jordan G., et al. Consensus statement on urethral trauma. Brit. I. Urol. Int. 2004; 93: 1195-1202.

2. Dorairajan L.N., Gupta H. and Kumar S. Pelvic fracture-associated urethral injuries in girls: experience with primary repair. Brit. J. Urol. Int. 2004; 94: 134-136.

3. Chapple C.R. and Damian P.N.G. Contemporary management of urethral trauma and post traumatic stricture. Curr. Opin. Urol. 1999; 9: 253-260.

4. Hafez A.T., EI-Assmy A., Sarhan O., et al. Perineal anastomotic urethroplasty for managing post traumatic urethral strictures in children: the long term outcome. Brit. J. Urol. Int. 2005; 95: 403-406.

5. Filho L.G.F., Carnevale J., Filho A.R.M., et al. Posterior urethral injuries and the Mitrofanoff principle in children. Brit. J. Urol. Int. 2003; 91: 402-405.
6. Webster G.D. and Ramon J. Repair of pelvic fracture posterior urethral defects using an elaborated perineal approach: Experience with 74 cases. J. Urol. 1991; 145: $744-748$.

7. Andrich D.E., O'Malley K.J., Summerton D.J., ct al. The type of urethroplasty for pelvic fracture urethral distraction defect cannot be predicted pre-operatively. J. Urol. 2003; 170: 464-467.

8. Andrich D.E., O'Malley K.J., Greenwell T.J., et al. Does urethrotomy jeopardise the outcome of urethroplasty? Brit. J. Urol. Int. 2003; 91(Suppl.2): 89.

9. Koraitim M.M. Post traumatic posterior urethral strictures in children: A 20 year experience. J. Urol. 1997; 157: 641-645.

10. Andrich D.E., Dunglison N., Greenwell T.J., et al. The long term results of urethroplasty. J. Urol. 2003; 170: 90-92.

11. Wood D.N., Nethercliffe J., Andrich D.E., et al. Peritoneal and perineal anatomy and surgical approaches. Brit. J. Urol. Int. 2004; 94: 719-737.

12. MacDonald M.F. and Santucci R.A. Review and treatment algorithm of open surgical techniques for management of urethral strictures. Urology. 2005; 65: 9-15.

13. Mundy A.R. Anastomotic urethroplasty. Brit. J. Urol. Int. 2005; 96: 921-944.

14. Koraitim M.M. Failed posterior urethroplasty: lessons learned. Urol. 2003; 62: 719-722.

15. Fellows G.J., Maranya G.A., Kaggwa S., et al. Sutureless membranous urethroplasty. Brit. J. Urol. 1996; 77: 307 -309.

16. Andrich D.E., Greenwell T.J. and Mundy A.R. Treatment of pelvic fracture-related urethral trauma: A survey of current practice in the UK. Brit. J. Urol. Int. 2005; 96: 127-130. 